October 2017, Volume 1, Issue 4

\title{
The Effect of Omega Fatty Acids on Bcl-2 Gene Expression and Protein Production in Cancerous Gastric Tissue
}

\author{
Homa Dokht Ghanbarzadeh ${ }^{1}$, Seyed Mojtaba Mohaddes ${ }^{2, *}$ \\ ${ }^{1}$ Department of Genetics, School of Basic Sciences, Islamic Azad University, Ahar, \\ Iran \\ ${ }^{2}$ Department of Medical Genetics, School of Medicine, Tabriz University of Medical \\ Sciences, Tabriz, Iran \\ * Corresponding author: Seyed Mojtaba Mohaddes, Department of Medical Genetics, \\ School of Medicine, Tabriz University of Medical Sciences, Tabriz, Iran. E-mail: mohad- \\ desmo@yahoo.com
}

DOI: $10.21859 /$ mci-01045

Submitted: 2 August 2017

Revised: 5 September 2017

Accepted: 20 September 2017

ePublished: 1 October 2017

Keywords:

Fatty Acids

Apoptosis

Stomach Neoplasms

Drug Resistance

\begin{abstract}
Introduction: Gastric cancer is the fourth common cancer and the second leading cause of death from cancer worldwide. Omega fatty acids are a group of non-saturated fatty acids of long chains derive from linolenic, linoleic and oleic fatty acids. The current study aimed at examining the possible effects of oral administration of omega-3, -6 and -9 fatty acids on gastric cancer cell apoptosis in patients with gastric adenocarcinoma via the evaluation of BCL2 gene and protein expression.

Methods: In the present case-control study, a total of 34 patients with gastric cancer referring to the Endoscopy Clinic at Tabriz University of Medical Sciences were selected and divided into 2 groups $(\mathrm{n}=17)$. In group 1 , patients were treated by platinum drugs without any supplementation and in group 2, patients were treated by platinum drugs supplemented with omega-3, -6 and -9 fatty acids over 3 courses, which each lasted 3 weeks. After stomach biopsy, RNA extraction, cDNA synthesis and real-time polymerase chain reaction (RT-PCR) were performed.

Results: The results showed that $\mathrm{Bcl}-2$ gene and BCL2 protein expression in patients who received omega-3, -6 and -9 fatty acids with chemotherapy was lower than those of the ones who not received omega fatty acids. Also, there was a significant decrease in Bcl-2 gene expression $(\mathrm{P}<0.05)$.

Conclusions: The oral administration of omega-3, -6 and -9 fatty acids with the chemotherapeutic drug cis-platinum in patients with gastric adenocarcinoma could decrease $\mathrm{Bcl}-2$ gene expression and BCL2 protein production in the cancerous gastric tissue.
\end{abstract}

(C) 2017. Multidisciplinary Cancer Investigation

\section{INTRODUCTION}

Gastric cancer is the fourth common cancer and the second leading cause of death in the world. Adenocarcinoma is the most common form of gastric cancer. Helicobacter pylori infections, smoking, salty diet and insufficient antioxidant intake are the factors contributing to developing this disease $[1,2]$. Chemotherapy is a very effective treatment modality in cancer therapy [3]. Chemotherapy reduces the tumor size in patients; however, this effect usually does not persist long time and the patient often deals with a problem of drug resistance in tumor cells [4]. The molecular drug resistance mechanism is not well-known in gastric cancer; however, understanding tumor development mechanism and promoting the effectiveness of chemotherapy by changing diet are very important to develop treatment methods and overcome drug resistance $[5,6]$. Omegas, non-saturated fatty acids of long chains, are essential to human body. Omega- 9 can be produced in the body, while omega- 3 and omega- 6 are the essential fatty acids and should be supplied by diet $[7,8]$. Omega-3, 6 and 9 fatty acids are derived from linolenic acid, linoleic acid and oleic acid, respectively [9, 10] and protect cardiovascular, reproductive, immune and nervous systems. Omegas are required to construct and repair cell membrane, as well as detoxify and supply nutritional elements [11]. They also are essential to produce prostaglandins, which regulate heartbeat, blood pressure, and fertility, and play an important role in the appropriate performance of immune system by con- 
trolling inflammations and infections [12]. Inflammation and environmental stress lead to apoptosis. Apoptosis plays an important role in growth regulation, immune responses, and abnormal cell clearance [13]. Apoptosis is necessary for eliminating cancer cells. Understanding apoptosis mechanism is necessary since it contributes to understanding pathogenesis, conditions occurred by disordered apoptosis, as well as developing the use of diet in chemotherapy and finding new drugs for targeting apoptosis genes and pathways $[14,15]$. The BCL2 protein as a member of Bcl-2 family has conserved its regulatory role in the apoptosis process over the evolutionary stages from C-elegans to mammals. BCL2 is specifically considered as an important anti-apoptotic protein and classified as an oncogene. The current study aime the effect of omega-3, -6 and -9 fatty acids on $\mathrm{Bcl}-2$ gene expression and protein production in cancerous gastric tissue.

\section{METHODS}

\section{Patients}

In the current case-control study, a total of 34 patients with gastric cancer referring to the Endoscopy Clinic at Tabriz University of Medical Sciences were selected and divided into 2 groups $(n=17)$. The patients were referred to an oncology specialist to start chemotherapy. Group 1 was treated by platinum drugs without administering any supplements, and the group 2 was treated by platinum drugs with an omega-3, -6 and -9 fatty acid supplement pills (Natural Factors Ultimate-Omega Factors 1200 mg with formulation of fish oil blend $400 \mathrm{mg}$, flaxseed oil $400 \mathrm{mg}$, and borage oil $400 \mathrm{mg}$ ) in a total amount of
$3600 \mathrm{mg}$ (three 1200-mg pills) per day over three courses (each course lasted 3 weeks). Then, consistent with the mandatory treatment follow-up, endoscopy followed by stomach biopsy was performed on the patients. Samples taken from patients were placed in nitrogen tanks and transferred to laboratory for assessment. Demographic and clinical information of the patients is presented in Table 1 . The study was approved by the biomedical Ethics Committee of Tabriz University of Medical Sciences and also the consent forms were obtained from the patients.

\section{Quantitative Real-time Polymerase Chain Reaction (qPCR) of Bcl-2 Gene}

RNAs were extracted from collected samples by the RNeasy kit (Bio Basic, Canada). The ratio of the absorbance at $260 \mathrm{~nm} / 280 \mathrm{~nm}$ was used to determine the extracted RNA quality. The RevertAidTM First strand cDNA synthesis kit (Takara, Japan) was used for cDNA synthesis. The housekeeping gene GAPDH was used as internal control by following sequences of primers: forward primer 5'GAAGGTGAAGGTCGGAGTC3', and reverse primer 3' GAAGATGGTGATGGGATTTC5' In this reaction, the constructed cDNA was used as the template and Smart-taq DNA polymerase (SYNLAB, Estonia) was employed for polymerase reaction. Primers were designed by Primer 3 and Oligo7 software programs. Sequences of primers for $\mathrm{Bcl}-2$ gene were as follows: forward 5'ATGTGTGTGGAGAGCGTCAA3', and reverse 3'TCTTCAGAGACAGCCAGGAGA5'. Real-time PCR was performed with a Rotor-gene 6000 (Corbett Robotics, Australia) using SYBER-green (Takara, Japan) master mix. Thermal cycling conditions were $95^{\circ} \mathrm{C}$ for 4 minutes; $95^{\circ} \mathrm{C}$ for $10 \mathrm{sec}$ onds; 45 cycles of $60^{\circ} \mathrm{C}$ for $60 \mathrm{sec}$.

Table 1: Demographic and Clinical Characteristics of the Patients

\begin{tabular}{|c|c|c|c|}
\hline Groups Clinical Factors & Control Group $(n=17)$ & Case Group $(n=17)$ & P Value \\
\hline Age (Years) & & & 0.235 \\
\hline$($ Means \pm SD $)$ & $67.5 \pm 11.21$ & $71.25 \pm 9.81$ & \\
\hline Sex & & & 0.695 \\
\hline Female $(n=15)$ & 8 & 7 & \\
\hline Male $(n=19)$ & 9 & 10 & \\
\hline Tumor size & & & 0.759 \\
\hline$<4 \mathrm{~cm}(\mathrm{n}=16)$ & 6 & 10 & \\
\hline$>4 \mathrm{~cm}(\mathrm{n}=18)$ & 10 & 8 & \\
\hline Original Site of Tumor & & & 0.098 \\
\hline $\operatorname{Upper}(\mathrm{n}=11)$ & 5 & 6 & \\
\hline Middle $(\mathrm{n}=13)$ & 8 & 5 & \\
\hline Lower $(\mathbf{n}=10)$ & 6 & 4 & \\
\hline Grade & & & 0.089 \\
\hline I $(\mathbf{n}=7)$ & 4 & 3 & \\
\hline II $(\mathbf{n}=11)$ & 6 & 5 & \\
\hline III $(\mathbf{n}=9)$ & 4 & 5 & \\
\hline $\operatorname{IV}(n=7)$ & 3 & 4 & \\
\hline Smoking & & & 0.085 \\
\hline Smoker $(n=12)$ & 5 & 7 & \\
\hline Non-smoker $(n=11)$ & 6 & 5 & \\
\hline Former Smoker $(n=11)$ & 4 & 7 & \\
\hline
\end{tabular}




\section{Immunohistochemical Study}

Indirect IHC was performed to confirm the expression of BCL2. Tissue samples were fixed in $4 \%$ formalin overnight, embedded in paraffin, sectioned at $4 \mu \mathrm{m}$ and stained with phycoerythrin (PE) conjugated anti-BCL2 antibody. After dewaxing, tumor tissue sections were rehydrated by sequential dipping into a series of bathes, for 3 minutes each involved: $95 \%$ ethanol, $75 \%$ ethanol, $50 \%$ ethanol and tap water. Antigen was retrieved in citrate buffer solution (Target Retrieval Solution, Agilent, Santa Clara, CA) at $37^{\circ} \mathrm{C}$ for 25 minutes and blocked with $1 \%$ BSA in phosphate-buffered saline (PBS) at room temperature for 30 minutes. Samples were stained for standard IHC.

\section{Statistical Analysis}

Statistical analysis was performed using SPSS software version 16.0 (SPSS Inc., Chicago, IL, USA). Normal distribution of $\mathrm{Bcl} 2 \mathrm{mRNA}$ expression levels was analyzed using the One-sample Kolmogorov-smirnov test. Independent $t$-test was used to compare the expression of $\mathrm{Bcl} 2$ in both groups. The non-parametric Wilcoxon-mann-whitney test was used to analyze the protein level alteration. $P$ values $<0.05$ were considered statistically significant.

\section{RESULTS}

\section{Patients}

In the present case-control study, $56 \%$ of all patients were male and $44 \%$ female. No significant difference was observed between the mean age of the control and case groups. There were also no significant difference $s$ between the groups in tumor size, original site of tumor, and grade and smoking status.

\section{Decreasing Bcl-2 Gene Expression}

Figure 1 shows the $B c l-2$ gene expression rate in the 2 groups of the study. As presented, the $\mathrm{Bcl}-2$ gene expression rate in the case group (patients received fatty acid supplement with chemotherapy) was significantly lower than that of the control group. The mean $\mathrm{Bcl}-2$ gene expression level was $2.101 .03 \pm$ in the control group and $1.280 .58 \pm$ in the case group $(\mathrm{P}<0.05)$.

\section{Assessment of BCL2 Protein Level}

The BCL2 expression was assessed semiquantitatively by IHC, using pathologists' scoring from - to $3+$. According to the current study criteria, samples with a negative and weak positive BCL2 expression scored - and +, respectively. For the cases who were difficult to score either - or +, score -/+ was given. Additionally, samples with a high BCL2 expression were also scored $2+$ and $3+$. The IHC results of BCL2 expression are shown in Table 2. Com- pared with the control group, the reduction of BCL2 protein level after treatment in the case group was not statistically significant.

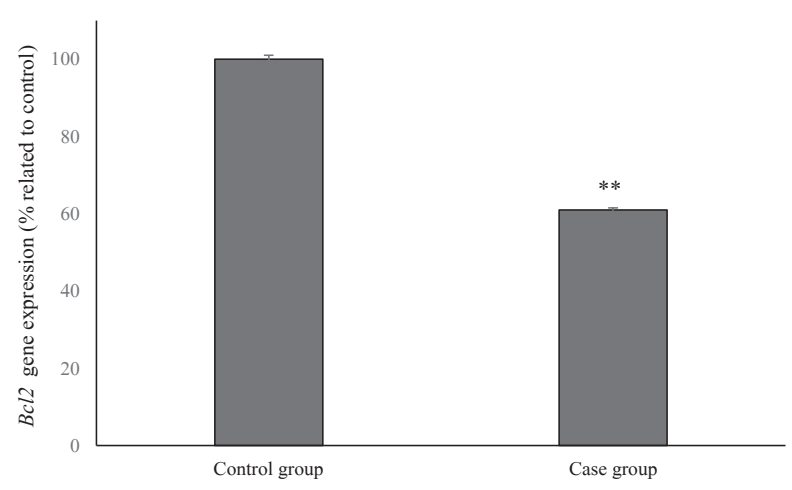

Figure 1: Comparison of the $B c l-2$ Transcription

Control group: received cisplatin without supplements, case Group: received cisplatin plus orally administered omega3, 6 and 9 supplements. ${ }^{* *}: \mathrm{P}<0.005$

Table 2: BCL2 Protein Expression Levels in Two Groups of Studied Patients

\begin{tabular}{lcccc}
\hline Sample & \multicolumn{2}{c}{ BCL2 Protein } & \multicolumn{2}{c}{ BCL2 Protein } \\
\hline & \multicolumn{2}{c}{ Control Group } & \multicolumn{2}{c}{ Case Group } \\
& Before & After & Before & After \\
$\mathbf{1}$ & + & $-/+$ & $2+$ & + \\
$\mathbf{2}$ & $2+$ & $-/+$ & $2+$ & - \\
$\mathbf{3}$ & $2+$ & + & $3+$ & $-/+$ \\
$\mathbf{4}$ & $2+$ & $-/+$ & $2+$ & - \\
$\mathbf{5}$ & $2+$ & $-/+$ & $2+$ & $-/+$ \\
$\mathbf{6}$ & + & - & + & - \\
$\mathbf{7}$ & $2+$ & - & $2+$ & $-/+$ \\
$\mathbf{8}$ & $2+$ & $-/+$ & $3+$ & - \\
$\mathbf{9}$ & $2+$ & + & $2+$ & - \\
$\mathbf{1 0}$ & + & - & + & $-/+$ \\
$\mathbf{1 1}$ & $2+$ & - & $2+$ & - \\
$\mathbf{1 2}$ & $2+$ & - & $2+$ & - \\
$\mathbf{1 3}$ & $2+$ & + & $3+$ & $-/+$ \\
$\mathbf{1 4}$ & $2+$ & - & $2+$ & $-/+$ \\
\hline $\mathbf{1 5}$ & $2+$ & - & $2+$ & - \\
$\mathbf{1 6}$ & + & - & + & - \\
$\mathbf{1 7}$ & $2+$ & $-/+$ & $2+$ & - \\
\hline & & & & \\
\hline
\end{tabular}

\section{DISCUSSION}

Chemotherapy is one of the standard treatment modalities for most cancers. However, this therapeutic method cannot always induce cell death or apoptosis in cancer cells and in most cases may lead to cancer recurrence, and finally death. Treating gastric cancer is still one of the challenges of oncology. The current study aimed examining the possible effects of oral administration of omega-3, -6 and -9 fatty acids on gastric cancer 
cell apoptosis in patients with gastric adenocarcinoma through studying $\mathrm{Bcl}-2$ gene expression and $\mathrm{BCL} 2$ protein production. Different studies have examined the impact of diet on cancer treatment. Currently, different roles has been recognized for dietary fatty acids including cell membrane and nuclear receptor modulation, cytoskeletal function, and signaling pathways regulation [16]. A variety of studies showed that polyunsaturated fatty acids (PUFAs) have cytotoxic effects on different types of cancer cells, and can be used as supplements to chemotherapy drugs. Hyde et al., showed that PUFAs can induce apoptosis in tumor cells by their ability to convert sphingomyelin to ceramide that triggers the release of pre-apoptotic proteins such as BCL2 [17], consistent with the results. Moreover, Comba et al. showed that PUFAs can be converted to eicosanoids by the enzymes cyclooxygenase (COX), lipoxygenase (LOX) and cytochrome P450 (CYP450) [7]. Using animal models, it has been demonstrated that $n-3$ PUFAs including eicosapentaenoic acid (EPA) and docosahexaenoic acid (DHA) induce apoptosis through MEK/ErK signaling pathway in breast cancer cells [18]. In addition, EPA and DHA reduce the expression of $\mathrm{Bcl} 2$ and procaspase-8, and activation of EGFR in human breast cancer cell lines [19]. EPA and DHA induce ROS accumulation in breast and pancreatic cancer cell lines and trigger caspase-8-dependent apoptosis in vitro and in vivo [20, 21]. DHA and EPA elevated the expression of the PTEN gene and its protein, peroxisome proliferator-activated receptor gamma (PPAR $\gamma$ ), in breast cancer cells. Increase of PPAR $\gamma$ resulted in inhibition of AKT-mTOR signaling phatways and cancer cell proliferation [22]. Gene $n$-3 PUFAs induce apoptosis and autophagy in prostate cancer cell lines through the AKT-mTOR signaling pathways [22]. In addition to apoptosis, PUFAs suppress inflammatory process and modulate CD4+ T-cell differentiation [23].

DHA and EPA reduce viability and induce apoptosis in gastric cancer cells through caspase-3. Adenosine A1 receptors, which involve in apoptosis, is up-regulated in response to DHA and EPA [15]. A study on colorectal cancer xenograft bearing mice has indicated that dietary $n-3$ PUFAs may enhance the effect of Chemotherapeutic agents and promote cancer cells' apoptosis via preventing Bcl2 and mt-p53 expression [24]. Another study has represent that omega- 3 and omega- 6 fatty acids induced apoptosis in colon cancer cells through a mitochondrial pathway, activation of caspase-3 and -9 , and inhibiting Bcl2 [25]. A study on stomach cancer cell line indicated that omega-3 fatty acid inhibited tumor growth and induced apoptosis in these cells [26]. Therefore, PUFAs are potent biological compounds that can prevent the growth of cancer cells. On the other hand, some studies indicated the cancer progression role of $n-6$ fatty acids. It has been shown that the AA-derived metabolite, 12-HETE, plays an important role in prostate cancer progression [27]. Furthermore, n-6 fat- ty acids induced proliferation in prostate cancer cells. A study on fatty acid compositions of phospholipids in mucosal gastric cancer cells also indicated that omega-6 fatty acid has a higher percentage compared with those of normal tissue due to the higher concentration of arachidonic acid [28]. It seems unsaturated fatty acids inhibit the apoptosis process in breast and prostate cancer [26]. The previous findings were consistent with the results of the current study. It can be concluded that the use of PUFAs, especially omega-3, as supplements to cis-platinum drugs may be effective to further stimulate apoptosis in gastric cancer cells due to decreased $B c l-2$ gene expression. These results may represent a better treatment response to chemotherapy in patients with gastric cancer. Further studies are required to conclude the effects of omega fatty acids as supplements on gastric cancer therapy.

\section{ACKNOWLEDGEMENTS}

The study received no financial support.

\section{CONFLICT OF INTEREST}

Authors declared no conflict of interest.

\section{ETHICS APPROVAL}

The research protocol was in harmony with the Declaration of Helsinki codes of ethics for biomedical research.

\section{REFERENCES}

1. Malekzadeh R, Derakhshan MH, Malekzadeh Z. Gastric cancer in Iran: epidemiology and risk factors. Arch Iran Med. 2009;12(6):576-83. PMID: 19877751

2. Wroblewski LE, Peek RM, Jr., Wilson KT. Helicobacter pylori and gastric cancer: factors that modulate disease risk. Clin Microbiol Rev. 2010;23(4):713-39. DOI: 10.1128/ CMR.00011-10 PMID: 20930071

3. Dicken BJ, Bigam DL, Cass C, Mackey JR, Joy AA, Hamilton SM. Gastric adenocarcinoma: review and considerations for future directions. Ann Surg. 2005;241(1):27-39. PMID: 15621988

4. Wingate DL. Experiments and Observations on the Gastric Juice and the Physiology of Digestion. Journal of the Royal Society of Medicine. 1990;83(12):816-. PMID: $\underline{\text { PMC } 1292986}$

5. Deans DAC, Tan BH, Wigmore SJ, Ross JA, de Beaux AC, Paterson-Brown $S$, et al. The influence of systemic inflammation, dietary intake and stage of disease on rate of weight loss in patients with gastro-oesophageal cancer. British Journal of Cancer. 2009; 100(1):63-9. DOI: 10.1038/sj.bjc.6604828 PMID: PMC2634686

6. Japanese Gastric Cancer A. Japanese gastric cancer treatment guidelines 2014 (ver. 4). Gastric Cancer. 2017;20(1):1-19. DOI: $10.1007 / \mathrm{s} 10120-016-0622-4$ PMID: PMC5215069

7. Comba A, Maestri DM, Berra MA, Garcia CP, Das UN, Eynard AR, et al. Effect of $\omega-3$ and $\omega-9$ fatty acid rich oils on lipoxygenases and cyclooxygenases enzymes and on the growth of a mammary adenocarcinoma model. Lipids in Health and Disease. 2010;9:112-. DOI: 10.1186/1476511X-9-112 PMID: PMC2959203

8. Drevon CA. Fatty acids and expression of adipokines. Biochim Biophys Acta. 2005;1740(2):287-92. DOI: 10.1016/j. bbadis.2004.11.019 PMID: 15949695

9. Bjerve KS. n-3 fatty acid deficiency in man. J Intern Med 
Suppl. 1989;731:171-5. PMID: 2565114

10. Harris WS. n-3 fatty acids and serum lipoproteins: human studies. Am J Clin Nutr. 1997;65(5 Suppl):1645S-54S. PMID: 9129504

11. Wei Y, Wang D, Topczewski F, Pagliassotti MJ. Saturated fatty acids induce endoplasmic reticulum stress and apoptosis independently of ceramide in liver cells. Am J Physiol Endocrinol Metab. 2006;291(2):E275-81. DOI: 10.1152/ ajpendo.00644.2005 PMID: 16492686

12. Makrides M, Duley L, Olsen SF. Marine oil, and other prostaglandin precursor, supplementation for pregnancy uncomplicated by pre-eclampsia or intrauterine growth restriction. Cochrane Database Syst Rev. 2006(3):CD003402. DOI: 10.1002/14651858.CD003402.pub2 PMID: 16856006

13. Reed JC. Mechanisms of Apoptosis. The American Journal of Pathology. 2000;157(5):1415-30. PMID: PMC1885741

14. Yin Y, Zhan WH, Peng JS, Zhao ZG. [Apoptosis of human gastric cancer cells induced by omega-3 polyunsaturated fatty acids]. Zhonghua Wei Chang Wai Ke Za Zhi. 2007;10(6):570-3. PMID: 18000782

15. Sheng H, Li P, Chen X, Liu B, Zhu Z, Cao W. Omega-3 PUFAs induce apoptosis of gastric cancer cells via ADORA1. Front Biosci (Landmark Ed). 2014;19:854-61. PMID: 24896321

16. Triff K, Kim E, Chapkin RS. Chemoprotective epigenetic mechanisms in a colorectal cancer model: Modulation by n-3 PUFA in combination with fermentable fiber. Current pharmacology reports. 2015;1(1):11-20. DOI: 10.1007/ s40495-014-0005-7 PMID: PMC4414264

17. Hyde CA, Missailidis S. Inhibition of arachidonic acid metabolism and its implication on cell proliferation and tumour-angiogenesis. Int Immunopharmacol. 2009;9(6):70115. DOI: 10.1016/j.intimp.2009.02.003 PMID: 19239926

18. Sun H, Hu Y, Gu Z, Owens RT, Chen YQ, Edwards IJ. Omega-3 fatty acids induce apoptosis in human breast cancer cells and mouse mammary tissue through syndecan- 1 inhibition of the MEK-Erk pathway. Carcinogenesis. 2011;32(10):151824. DOI: $10.1093 /$ carcin/bgr132 PMID: 21771724

19. Corsetto PA, Montorfano G, Zava S, Jovenitti IE, Cremona A, Berra B, et al. Effects of n-3 PUFAs on breast cancer cells through their incorporation in plasma membrane. Lipids in Health and Disease. 2011;10:73-. DOI: 10.1186/1476511X-10-73 PMID: PMC3127786
20. Kang KS, Wang P, Yamabe N, Fukui M, Jay T, Zhu BT. Docosahexaenoic acid induces apoptosis in MCF-7 cells in vitro and in vivo via reactive oxygen species formation and caspase 8 activation. PLoS One. 2010;5(4):e10296. DOI 10.1371/journal.pone.0010296 PMID: 20421971

21. Fukui M, Kang KS, Okada K, Zhu BT. EPA, an omega-3 fatty acid, induces apoptosis in human pancreatic cancer cells: role of ROS accumulation, caspase- 8 activation, and autophagy induction. J Cell Biochem. 2013;114(1):192-203. DOI: 10.1002/jcb.24354 PMID: 22903547

22. Shin S, Jing K, Jeong S, Kim N, Song KS, Heo JY, et al. The omega-3 polyunsaturated fatty acid DHA induces simultaneous apoptosis and autophagy via mitochondrial ROS-mediated Akt-mTOR signaling in prostate cancer cells expressing mutant p53. Biomed Res Int. 2013;2013:568671. DOI: 10.1155/2013/568671 PMID: 23841076

23. Bi X, Li F, Liu S, Jin Y, Zhang X, Yang T, et al. omega-3 polyunsaturated fatty acids ameliorate type 1 diabetes and autoimmunity. J Clin Invest. 2017;127(5):1757-71. DOI 10.1172/JCI87388 PMID: 28375156

24. Tan YZ, Huang WG, Chen FY, Li J, Zhou JY, Wang LJ, et al. $\mathrm{n}-3$ Polyunsaturated fatty acids enhance the antitumor effect of 5-fluorouracil by inhibiting bcl-2 and mutant-p53. Eur J Lipid Sci Technol. 2013;115(12):1483-91. DOI: 10.1002/ ejlt.201300017

25. Zhang C, Yu H, Shen Y, Ni X, Shen S, Das UN. Polyunsaturated fatty acids trigger apoptosis of colon cancer cells through a mitochondrial pathway. Arch Med Sci. 2015;11(5):108194. DOI: 10.5114/aoms.2015.54865 PMID: 26528354

26. Peck B, Schug ZT, Zhang Q, Dankworth B, Jones DT Smethurst E, et al. Inhibition of fatty acid desaturation is detrimental to cancer cell survival in metabolically compromised environments. Cancer Metab. 2016;4:6. DOI 10.1186/s40170-016-0146-8 PMID: 27042297

27. Yang P, Cartwright CA, Li JIN, Wen S, Prokhorova IN Shureiqi I, et al. Arachidonic acid metabolism in human prostate cancer. International Journal of Oncology. 2012;41(4):1495-503. DOI: 10.3892/ijo.2012.1588 PMID: PMC3982713

28. Ahn J, Park IS, Lee KS, Kim SY, Chung EJ, Kim J, et al. Fatty acid patterns in gastric mucosa of stomach cancer patients. Yonsei Med J. 2001;42(2):220-6. DOI: 10.3349/ ymj.2001.42.2.220 PMID: 11371111 